\title{
An Anucleolate Mutant of the Cellular Slime Mould Dictyostelium discoideum*
}

\author{
By S. ISHIDA \\ Biological Laboratory, Kyoto University of Education, \\ Fushimi, Kyoto 6I 2, Japan \\ AN D \\ Y. MAEDA AND I. TAKEUCHI \\ Department of Biology, Faculty of Science, Kyoto University, \\ Kyoto 606, Japan
}

(Received 23 October 1973)

SUMMARY

An anucleolate mutant (AN) was isolated from the cellular slime mould, Dictyostelium discoideum. The AN developed normally until the beginning of culmination, when development stopped and no differentiation of the spore or stalk cell occurred. The AN had nucleoli at the vegetative stage, but lost them after formation of a cell mass, in contrast to the wild type (WT) which possessed them throughout development. AN cells disaggregated from a slug, reconstructed nucleoli and resumed vegetative growth. Difference in tetrazolium reduction between the prestalk cell and the pre-spore cell, as observed in the WT, was not detected in the AN, although vacuoles specific to the pre-spore cell were formed. When the WT and AN cells were mixed, they aggregated together, but no interaction in cell differentiation was observed. The roles of nucleoli in the development of this organism are discussed.

\section{INTRODUCTION}

During the growth phase of Dictyostelium discoideum, an amoeba grows and multiplies, feeding on bacteria. After ceasing to feed, individual amoebae aggregate and form a cell mass with a slug shape. The slug migrates on the substratum for a time, until it constructs a fruiting body consisting of a mass of spores and a supporting cellular stalk.

Various kinds of morphogenetically deficient mutants of this organism have been isolated. Since they can grow normally but stop morphogenesis at a certain stage of development, analytical studies of such mutants will provide valuable information for elucidating the developmental process.

During an attempt to isolate and characterize such mutants (Ishida, 1967), a fruitless mutant was obtained which had nucleoli during the vegetative stage but lost them after cell aggregation. The present paper describes this anucleolate mutant.

\section{METHODS}

Organism. Dictyostelium discoideum, strain NC4, and an anucleolate mutant isolated therefrom were used throughout this work.

Culture methods. Wild-type amoebae were grown at $2 \mathrm{I}{ }^{\circ} \mathrm{C}$ with Escherichia coli on a standard nutrient agar medium (Bonner, 1947). Since anucleolate mutant amoebae had great

* Unfortunately the mutant has been lost due to difficulty in transplantation. 
difficulty in growing on the same medium, a nutrient-poor agar medium, LP, containing $0.1 \%$ lactose and $0.1 \%$ peptone, was used. To obtain cell masses at various stages of development, amoebae were collected at the stationary growth phase and were washed free of bacteria by repeated centrifugations in chilled standard salt solution (Bonner, 1947). The washed amoebae were placed on non-nutrient agar and incubated until the required stage of development was reached.

Electronmicroscopy. Cells or cell masses at various stages of development were fixed in I $\% \mathrm{OsO}_{4}$, dehydrated, and embedded in epoxy resin. The detailed procedures were described by Maeda \& Takeuchi (1969).

Histochemistry. Differential staining of the pre-stalk and the pre-spore cells of a slug was done with neotetrazolium (Dajac) or nitro-blue tetrazolium (Dajac) in the presence of succinate, according to the method described by Mine \& Takeuchi (I967). When the former was used, the reaction was carried out in the presence of $12.5 \mathrm{mM}-\mathrm{KCN}$.

\section{RESULTS}

\section{Isolation of an anucleolate mutant}

An anucleolate mutant was isolated by the conventional method for the isolation of morphogenetically deficient mutants (Ishida, 1967). Spores of haploid NC4 were suspended in a sterilized $0.01 \%$ solution of aerosol OT (American Cyanamid) in 30 mm-tris buffer, $\mathrm{pH} \mathrm{7.3} \mathrm{(Takeuchi,} \mathrm{I963),} \mathrm{and} \mathrm{0.} \mathrm{I} \mathrm{ml}$ of a suspension containing 200 to 400 spores was spread on an LP medium. The plate was exposed to a dose of u.v. which killed about $95 \%$ of the spores. A suspension of Escherichia coli was added to the plate, and clones undergoing aberrant morphogenesis were isolated. Among the mutants thus isolated, there was found the anucleolate mutant described below.

\section{Development of the mutant}

Development of the AN was not distinguishable from that of the WT up to an early stage of culmination, when the AN rose in the air and assumed the shape of a Mexican hat. Then, unlike the WT, it stopped further development, gradually flattened on the substratum, and finally disintegrated (Fig. I). The flattened cell mass contained no stalk or spore cells, but consisted of undifferentiated amoebae which gradually became immotile. The accumulation of a slime sheath was occasionally observed around the basal region of the cell mass (Fig. 2).

\section{Ultrastructure of the mutant}

The fine structure of the AN cells was examined at various developmental stages to compare them with the WT cells. The most distinct difference between the two was found in nucleoli. In contrast to the WT which has nucleoli throughout development (Maeda \& Takeuchi, I969), slug cells of the AN contained either no nucleoli or only their remnants (Figs. 3, 4). On the other hand, the vegetative amoebae of both the AN and WT had normal nucleoli. During aggregation the AN cells partially lost ribosome-like granules in nucleoli and the electron density of their fibrous matrix decreased considerably (Fig. 5).

Besides nucleoli, considerable differences in fine structure were also observed between the WT and AN. The AN slug cells contained less rough-surfaced endoplasmic reticula and ribosomes than the WT. This is probably attributable to the absence in the former of nucleoli which are considered to be responsible for the synthesis of ribosomal RNA. The pre-spore specific vacuoles (PSV), which are present only in the WT pre-spore cells (Maeda \& Takeuchi, 

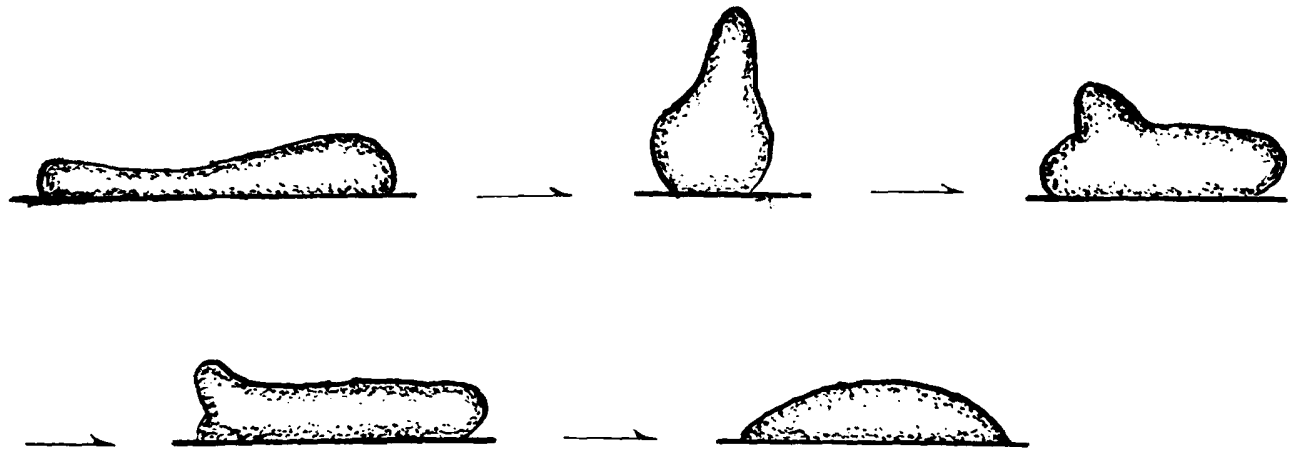

Fig. I. Schematic representation of the development of the anucleolate mutant in the early stage of culmination.

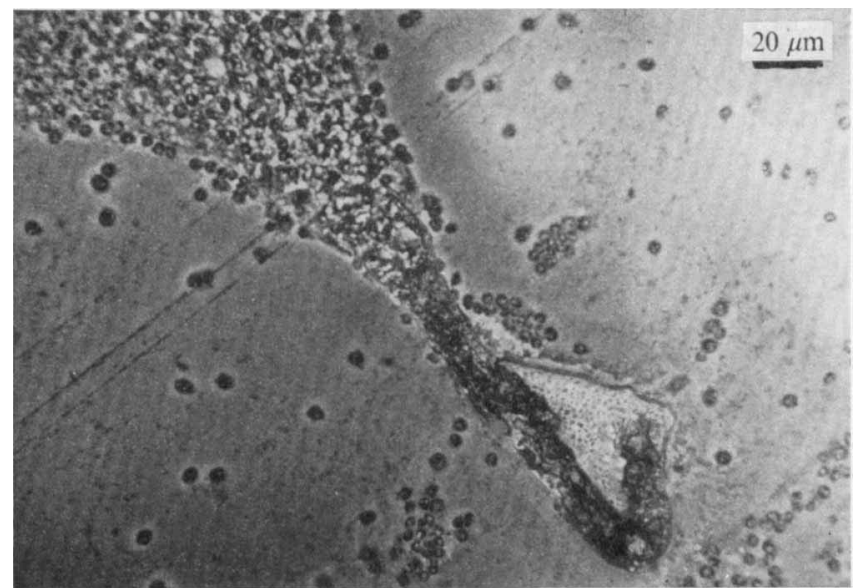

Fig. 2. A phase-contrast photomicrograph of a flattened cell mass of the AN, squashed obliquely. It consists of undifferentiated amoebae. The accumulation of slime sheath is observed around the basal region.

1969; Hohl \& Hamamoto, 1969), were also found in the AN, although there they were squarer and had more breaks in the lining membrane, as compared with those in a WT strain (Fig. 3). The two also differed in cell contact. While the pre-stalk cells of the WT were in close contact, those of the AN were loosely packed, having large intercellular spaces (Fig. 4). The pre-spore cells of both strains were likewise loosely packed (Fig. 3).

\section{Histochemical studies of the mutant}

It is known that three different regions of the slug, i.e. the tip, the pre-stalk and the prespore, were distinguished by staining with neotetrazolium or nitro-blue tetrazolium (Mine \& Takeuchi, 1967). Whether or not such regional differentiation occurs in the AN slug was examined. Although the pre-stalk and the pre-spore regions of the WT slugs were differentially stained with neotetrazolium in the presence of $\mathrm{KCN}$, the AN slugs developed almost no colour throughout, even after $2 \mathrm{~h}$ of incubation (Fig. 6). Likewise, while the tip region of a WT slug was characterized by strong staining with nitro-blue tetrazolium, only weak staining was seen in the extreme tip of an AN slug (Fig. 6). Thus differentiation of the three regions, as revealed in a WT slug by tetrazolium reduction, was not clearly observed in an AN slug. 

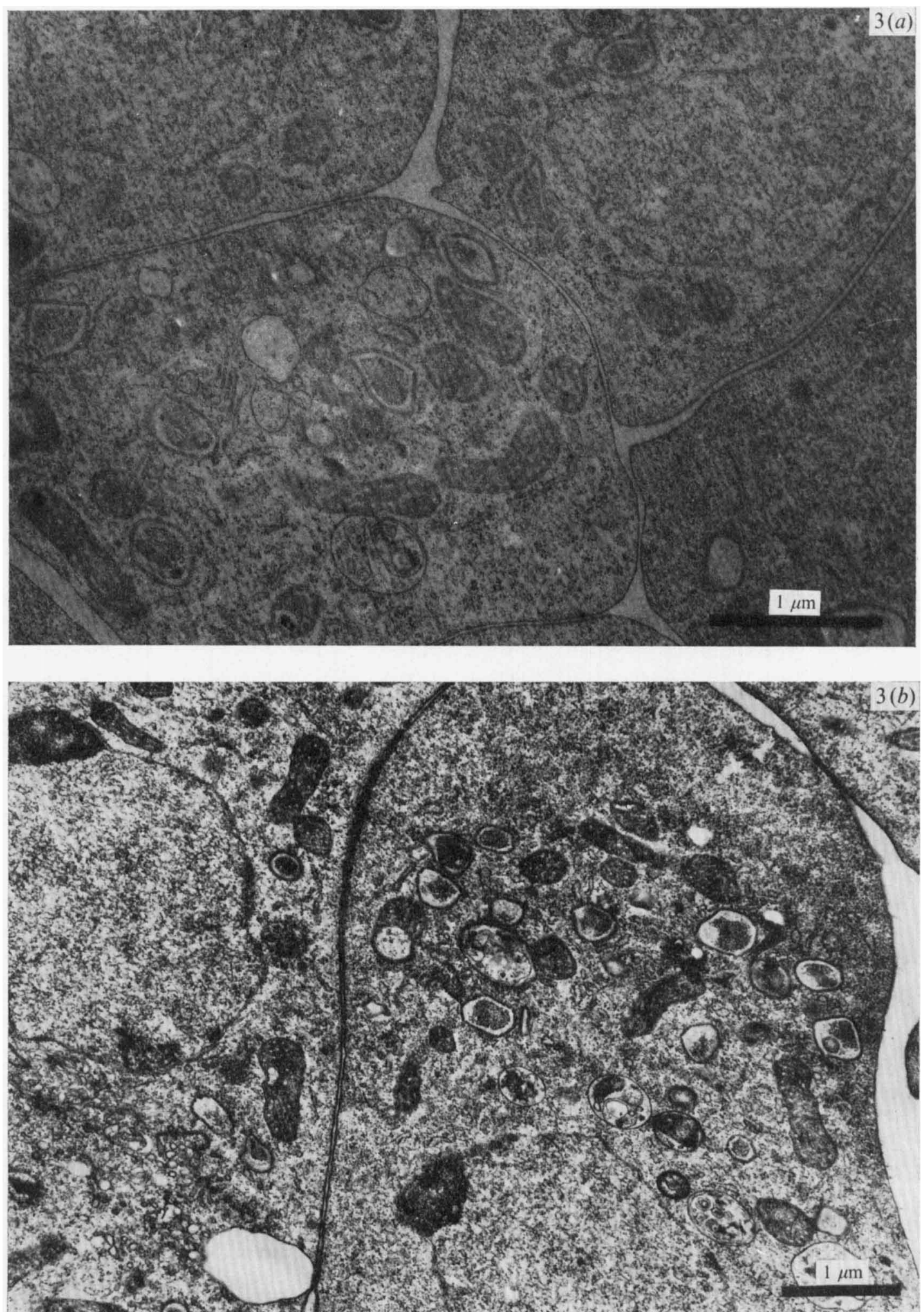

Fig. 3. Electron micrographs of the pre-spore cells in slugs of the AN(a) and the WT(b). An AN cell has no nucleoli in the nucleus. The pre-spore specific vacuoles are observed both in AN and WT cells, but those in the former are squarer than in the latter. 

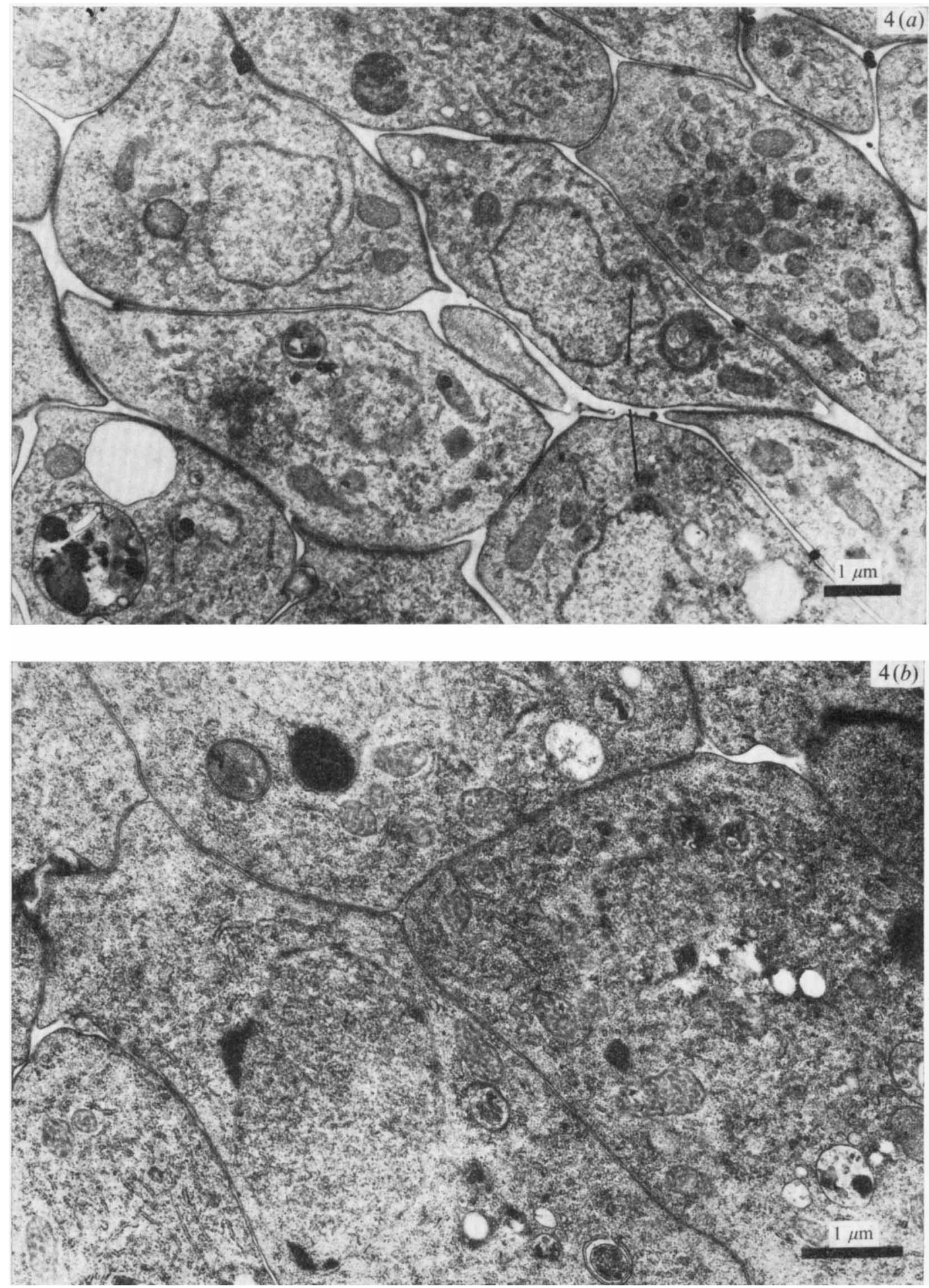

Fig. 4. Electron micrographs of the pre-stalk cells in slugs of the AN(a) and the WT(b). An AN cell has either no nucleoli or only the remnant (arrows), as in the pre-spore cell shown in Fig. 3. AN cells are more loosely packed with larger intercellular spaces than WT cells. 


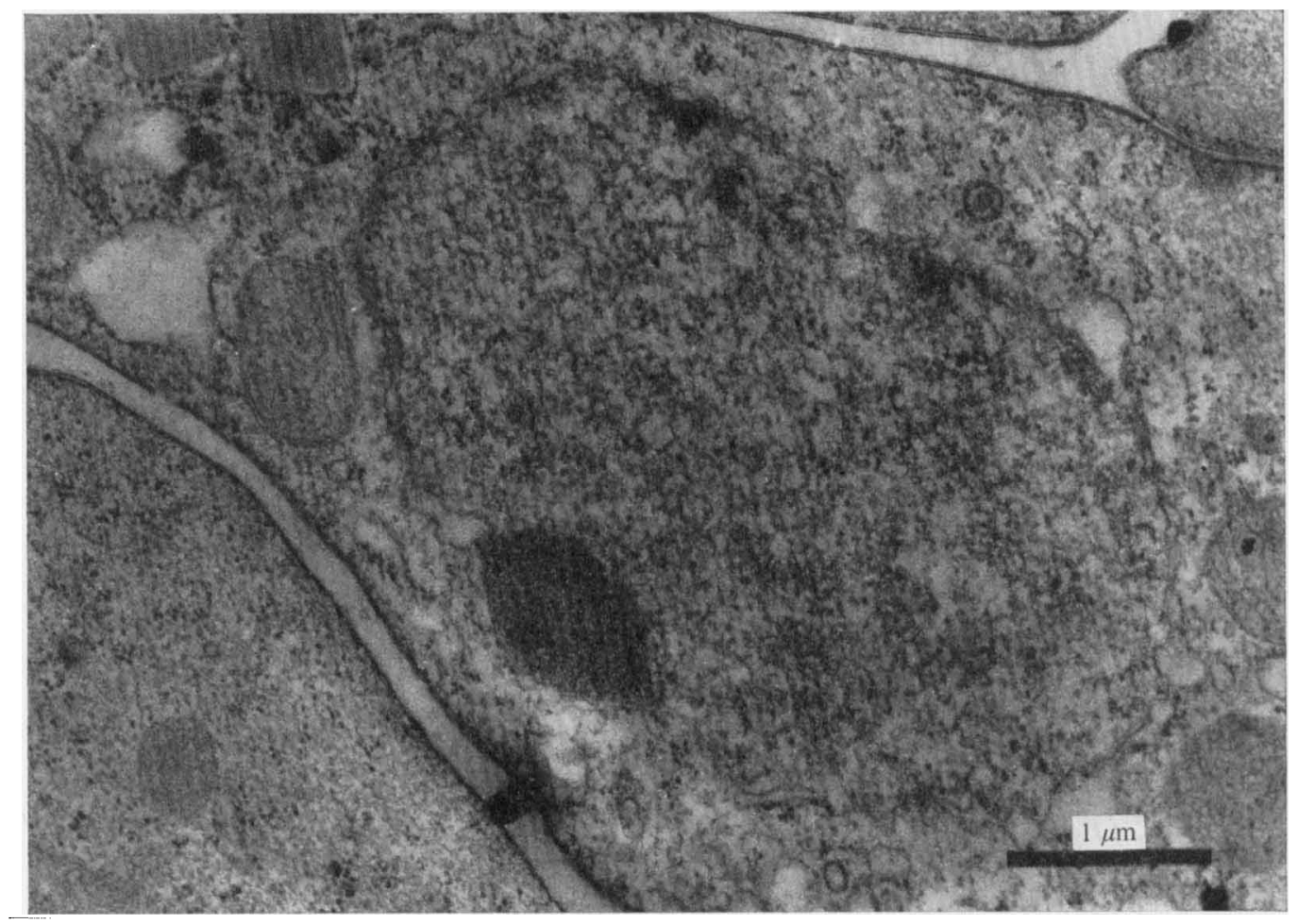

Fig. 5. An electron micrograph of a cell aggregate of the AN. A nucleolus which is disappearing is seen to contain a few ribosome-like granules.

NT

WT

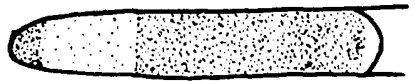

AN

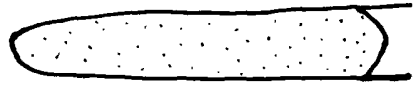

$\mathrm{nBT}$

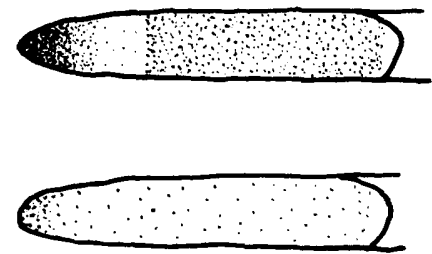

Fig. 6. Tetrazolium reactions with slugs of the WT and of the AN. Schematic drawings of the staining after I h of incubation. NT, incubation in $0.1 \%$ neotetrazolium containing $12.5 \mathrm{mM}-\mathrm{KCN}$; nBT, incubation in $0.1 \%$ nitro-blue tetrazolium.

\section{Regulation of appearance and disappearance of nucleoli in the mutant}

To determine whether the disappearance of nucleoli in the AN slug cells was attributable to formation of the cell mass or merely to cell ageing after feeding ceased, the washed AN vegetative amoebae were placed on non-nutrient agar, at a population density low enough not to form a cell aggregate. After $24 \mathrm{~h}$ of incubation (which ensures the disappearance of nucleoli in the aggregated cell mass), cells were fixed in $\mathrm{I} \% \mathrm{OsO}_{4}$ and observed. All the unaggregated cells had nucleoli, which indicated that formation of a cell mass was responsible for the disappearance of nucleoli.

Whether or not nucleoli once lost in the AN slug cells were re-formed after disaggrega- 


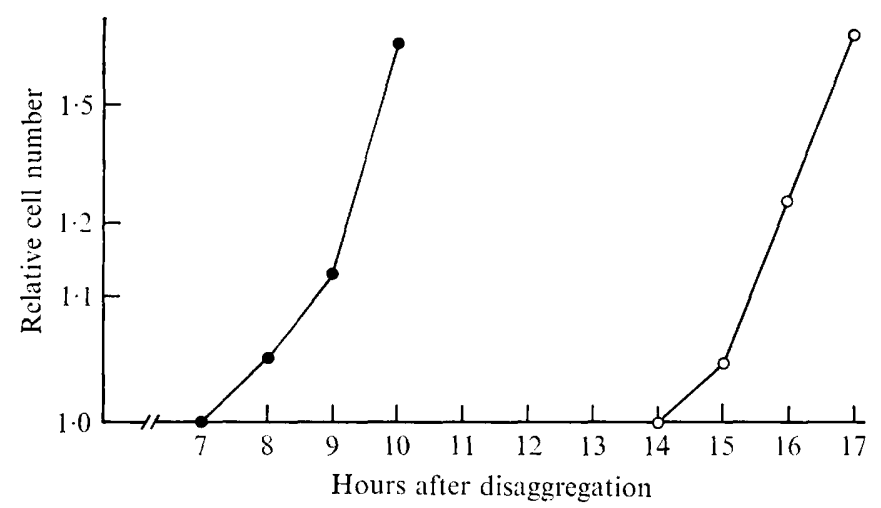

Fig. 7. The growth curves of disaggregated slug cells. A drop of the suspension of Escherichia coli containing a few disaggregated cells of the AN or the WT was deposited on non-nutrient agar and incubated at $2 \mathrm{I}{ }^{\circ} \mathrm{C}$. After various times of incubation, the number of cells in each spot was counted. , WT; O, AN.

tion of the slug was examined in the following way. AN slugs collected at the late migration stage were disaggregated in a $0 . \mathrm{I} \%$ pronase solution containing $25 \mathrm{~mm}$-dimercaptopropanol (Takeuchi \& Yabuno, 1970). After being washed, disaggregated cells were incubated with Escherichia coli on non-nutrient agar. After $24 \mathrm{~h}$ of incubation, the cells were fixed and examined. Nucleoli were found in all cells. The growth curve of the disaggregated AN slug cells was compared with that of the WT slug cells. As shown in Fig. 7, the WT cells began to divide after $8 \mathrm{~h}$ of incubation, while the AN cells did not divide before I $5 \mathrm{~h}$. After the first cell division, both the WT and AN cells multiplied with the same generation time. The time difference of $7 \mathrm{~h}$ between the two strains before the resumption of cell growth probably reflects the time needed for a cell to reconstruct its nucleoli.

\section{Interactions in morphogenesis between $A N$ and WT cells}

In order to study possible interactions in cell differentiation, washed vegetative amoebae of the two strains were mixed in a certain proportion. They aggregated and formed a slug normally. The fruiting bodies they constructed, however, showed considerable variations according to the ratio of the WT to AN cells (Fig. 8). When the ratio was over 9 WT to I AN, the fruiting bodies formed were apparently normal, but microscopic observations revealed that the spore mass contained some undifferentiated, abnormal-looking cells besides well differentiated spores (Fig. 8a). They were round, immotile cells which were smaller and appeared darker under a phase-contrast microscope than ordinary undifferentiated amoebae. On subculture, these cells could not grow. They looked like AN cells dispersed from the flattened cell mass after abortive culmination (see Fig. 2). That they were really AN was supported by the finding that only WT clones were produced by culturing single spores obtained in the above culture. These facts indicate that AN cells could not differentiate into spores even when they were surrounded by a large number of WT cells.

In proportion to the decrease in the ratio of WT cells, the number of abnormal cells increased with the concomitant shortening of the stalk (Fig. 8b). This indicates that AN cells could not differentiate into stalk cells as well as into spores. In contrast, differentiation of WT cells into spores or stalk cells was always normal even in the presence of a large number of AN cells (Fig. $8 b, c$ ). 
Ratio of the WT to the A fruiting AN cells body formed

9
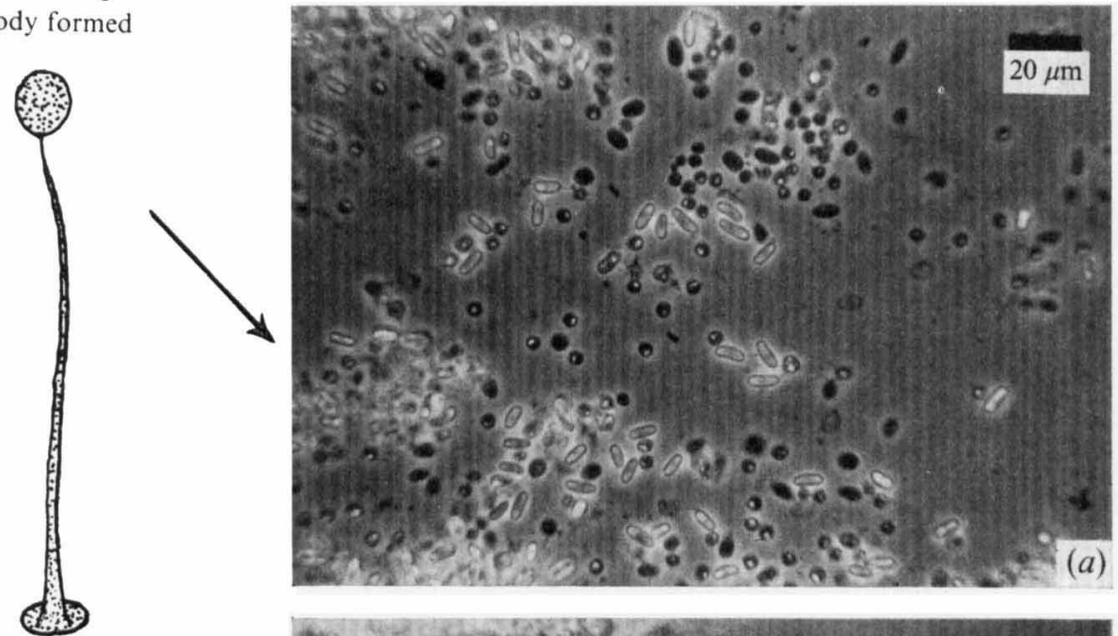

1
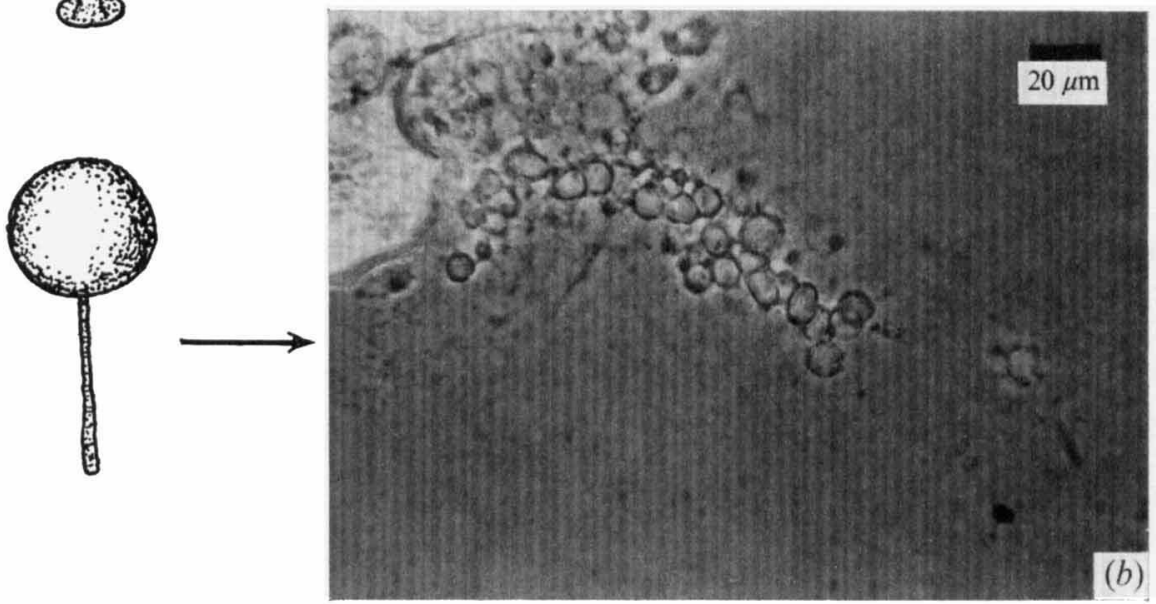

(b)

$0 \cdot 3$
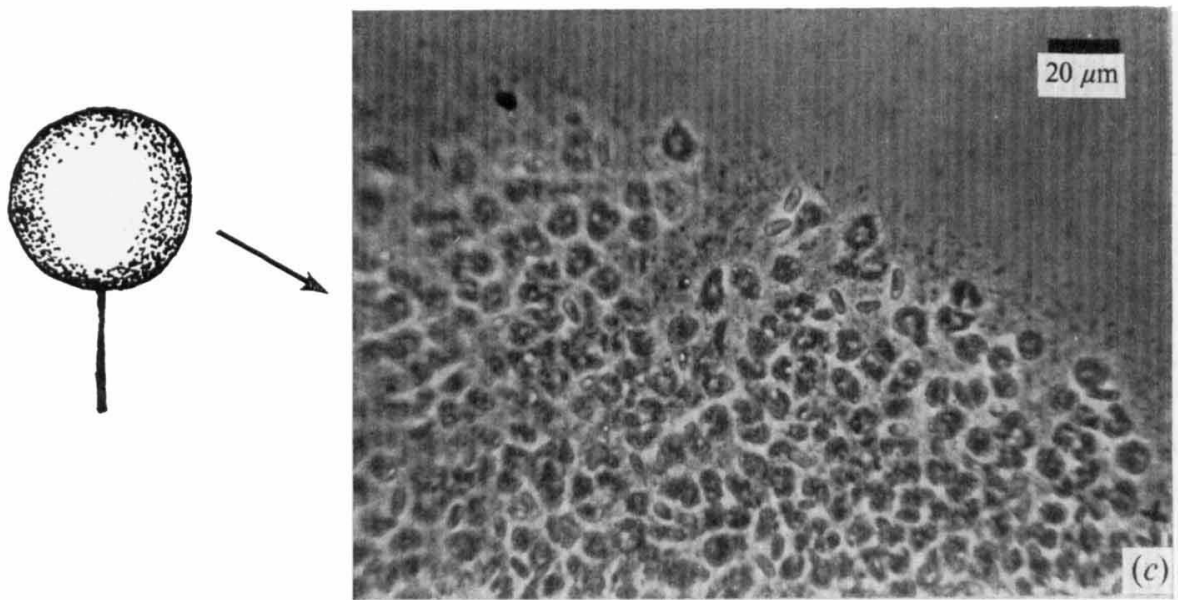

Fig. 8. Morphogenesis of mixed populations of WT and AN cells. Schematic drawings of fruiting bodies formed and photomicrographs of cells composing a part (indicated by arrow) of the fruiting bodies. 


\section{DISCUSSION}

The anucleolate mutant (AN) of Dictyostelium discoideum described in the present paper had normal nucleoli during the vegetative stage, but lost them after formation of a cell mass. The time of their disappearance coincides with the stage in which considerable structural changes in nucleoli occur in wild-type (WT) cells. It was known that ribosome-like granules contained in nucleoli of the vegetative amoebae are temporarily lost during the aggregation stage and that granules, though somewhat different in size and electron density, reappear in the later stages (Maeda \& Takeuchi, 1969). Such morphological changes of nucleoli accord well with the biochemical changes in rRNA. According to Cocucci \& Sussman (1970), at least $75 \%$ of the rRNA synthesized during cell growth is degraded during morphogenesis and is replaced by newly synthesized rRNA. Considering these facts, loss of nucleoli in AN slug cells is probably attributable to their inability to synthesize new ribosomes during morphogenesis, after the degradation of ribosomes formed during cell growth. When an AN slug is disaggregated, cells begin to synthesize the latter type of ribosomes, resulting in the reappearance of nucleoli.

Although AN cells lost nucleoli at the early stages of morphogenesis, a considerable number of ribosomes (though fewer than in WT cells) were still present in the later stages. The fact that spore and stalk-cell differentiation was nevertheless suppressed in the mutant suggests that such differentiation required the presence of ribosomes synthesized during morphogenesis. This supports the notion of Cocucci \& Sussman (1970) that these ribosomes are functionally different from those synthesized during cell growth.

Despite the loss of nucleoli, AN slugs continued normal migration for a long period. Migration was normal in spite of the fact that their anterior pre-stalk cells were less cohesive and had larger intercellular spaces than those of the WT. Differentiation between the pre-stalk cell and the pre-spore cell proceeded in the mutant to a certain extent; AN as well as WT slugs formed the pre-spore specific vacuoles in their pre-spore cells. However, no differential staining of AN slugs was observed with tetrazolium reduction.

Morphogenesis of the mixed population of WT and AN indicated that WT cells could not restore the ability of $\mathrm{AN}$ cells to differentiate into spores or stalk cells, even when the former were present in large excess. On the other hand, AN cells in the cell mass were able to provide an adequate environment for the WT cells to undergo normal differentiation in spite of their inability to differentiate alone.

\section{REFERENCES}

BONNER, J. T. (I947). Evidence for the formation of cell aggregates by chemotaxis in the development of the slime mold, Dictyostelium discoideum. Journal of Experimental Zoology ro6, I-26.

Cocucci, S. M. \& SusSman, M. (1970). RNA in cytoplasmic and nuclear fractions of the cellular slime mold amoebas. Journal of Cell Biology 45, 399-407.

Hohl, H. R. \& Hamamoto, S. T. (1969). Ultrastructure of spore differentiation in Dictyostelium; the prespore vacuole. Journal of Ultrastructure Research 26, 442-453.

IsHIDA, S. (1967). Morphogenetically deficient mutants of the cellular slime mould. Master's thesis, Osaka University, Japan.

MAEDA, Y.\& TAKEUCHI, I. (1969). Cell differentiation and fine structures in the development of the cellular slime molds. Development, Growth and Differentiation II, 232-245.

Mine, H. \& TAKeuChI, I. (1967). Tetrazolium reduction in slime mold development. Annual Report of Biological Works, Faculty of Science, Osaka University 15, 97-1 I I.

TAKEUCHI, I. (1963). Immunochemical and immunocytochemical studies on the development of the cellular slime mold Dictyostelium mucoroides. Developmental Biology 8, I-26.

TAKEUCHI, I. \& YABUNO, K. (1970). Disaggregation of slime mold pseudoplasmodia using EDTA and various proteolytic enzymes. Experimental Cell Research 61, I83-190. 